\title{
Novos táxons em Piezocerini e Ibidionini (Coleoptera, Cerambycidae)
}

\author{
Ubirajara R. Martins 1,3 \\ Maria Helena M. Galileo ${ }^{2,3}$
}

\begin{abstract}
New taxa in Piezocerini and Ibidionini (Coleoptera, Cerambycidae). New taxa described: Piezocerini - Piezosecus gen. nov., type species, P. tymaiuba sp. nov. (Brazil, São Paulo); Ibidionini - Gnomibidion variabile sp. nov. (Brazil, Mato Grosso), and Palpibidion gen. nov., type species, P. minimum sp. nov. (Brazil, Rondônia).
\end{abstract}

KEywords. Cerambycidae; Coleoptera; Ibidionini; Piezocerini; Neotropical.

\section{INTRODUÇÃO}

A tribo Piezocerini foi revista por Martins (1976) e, recentemente, foram descritas por GALILEO \& MARTINS (2000) espécies nos gêneros Hemilissa Pascoe, 1858 e Piezocera Audinet-Serville, 1834; dentre o material recebido para identificação deparamos com um gênero novo e uma espécie nova, Piezosecus gen. nov., P. tymaiuba sp. nov., que são descritos.

A tribo Ibidionini também foi revista por MARTins (19671971), organizada em cinco divisões; posteriormente, foi objeto de diversos trabalhos com acréscimos, por exemplo, MARTINS (1971), NAPP \& MARTINS (1985a, 1986b), MARTINS \& NAPP (1986a, 1986b) e Martins \& GaliLeo (1999). Acrescentamos agora uma espécie nova de Gnomibidion (III ${ }^{\text {a }}$ Divisão), G. variabile $\mathbf{s p . ~}$ nov., e Palpibidion gen. nov. (IV ${ }^{a}$ Divisão), P. minimum sp. nov.

$\mathrm{O}$ material arrolado no texto pertence às seguintes instituições: Departamento de Zoologia, Universidade Federal do Paraná, Curitiba (DZUP); Museu Nacional, Universidade Federal do Rio de Janeiro, Rio de Janeiro (MNRJ); Museu Paraense Emílio Goeldi, Belém (MPEG) e Museu de Zoologia, Universidade de São Paulo, São Paulo (MZSP).

\section{Piezocerini}

Piezosecus gen. nov.

Espécie-tipo: Piezosecus tymaiuba sp. nov.

Etimologia. Grego, piezo $=$ deprimido; latim, secus $=$ diferente, diverso de Piezocera, gênero-tipo da tribo.
Fronte alveolada. Fóveas laterais muito profundas. Lobos oculares superiores com quatro ou cinco fileiras de omatídios, ligeiramente adelgaçados atrás da inserção das antenas. Tubérculos anteníferos projetados, acuminados no ápice. Antenas dos machos atingem a ponta dos élitros na extremidade do antenômero VIII; das fêmeas, no ápice do antenômero X. Escapo cilíndrico, robusto, deprimido no lado superior da base, densamente pontuado, alveolado e sem cicatriz apical; comprimento igual a dois terços do antenômero III. Antenômero III não-expandido na extremidade, com as carenas dorsais apenas indicadas; comprimento um terço mais longo que o IV. Antenômeros V-XI cilíndricos, alongados, não-expandidos na extremidade e com comprimentos subiguais; lado externo com áreas sensoriais deprimidas.

Protórax mais largo que longo; pouco mais constrito na base do que no ápice; com tubérculo no meio dos lados. Pronoto com cinco gibosidades discretas: a centro-posterrior mais alongada e lisa. Processo prosternal triangular, laminiforme na extremidade. Cavidades coxais anteriores aberta atrás. Processo prosternal (Fig. 2) triangular, acentuadamente estreitado em direção ao ápice. Processo mesosternal (Fig. 2) triangular.

Élitros pontuados, aplanados e com as extremidades arredondadas; pêlos inseridos no interior dos pontos.

Trocanteres dos machos sem modificações. Fêmures fusiformes. Metatíbias sem carenas e não expandidas para o ápice. Metatarsômero I longo; mais longo que o II e III reunidos.

Discussão. Piezosecus pertence à subtribo Piezocerina e separa-se de todos os gêneros com cavidades coxais anteriores abertas (MARTINs 1976) pelos processos pro- e mesosternal

\footnotetext{
1. Museu de Zoologia, Universidade de São Paulo. Caixa Postal 42594, 04299-970 São Paulo-SP, Brasil.

2. Museu de Ciências Naturais, Fundação Zoobotânica do Rio Grande do Sul. Caixa Postal 1188, 90001-970 Porto Alegre-RS, Brasil.

3. Pesquisador do CNPq.
} 


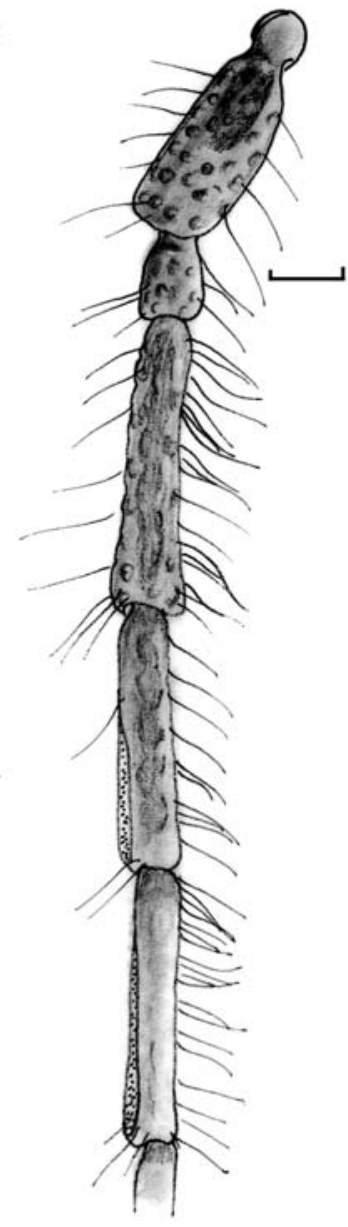

1

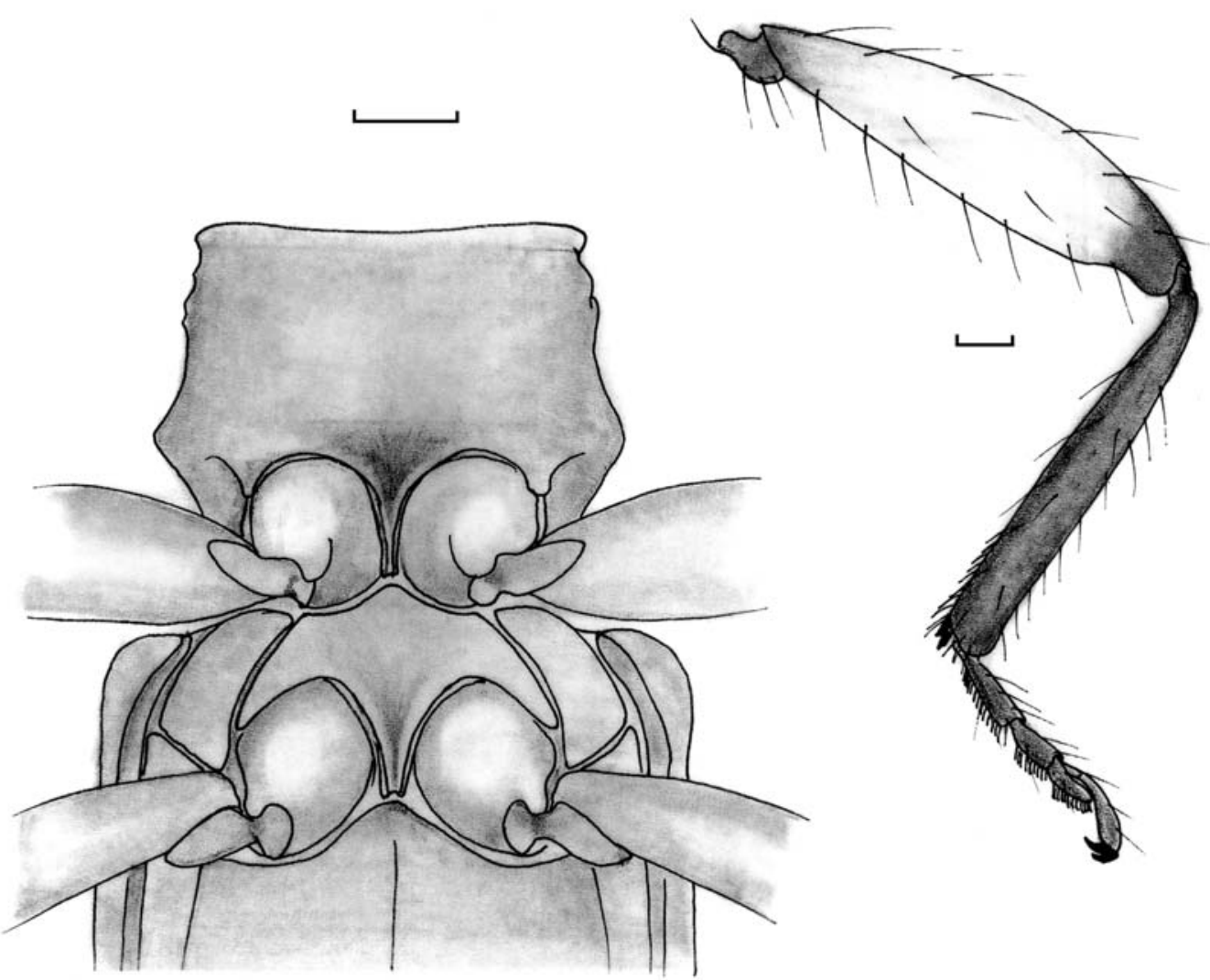

2

Figs. 1-3. Piezosecus tymaiuba sp. nov.: 1, antenômeros basais; 2, esternos torácicos; 3, perna posterior. Barra=1 mm.

acentuadamente acuminados para o ápice. O antenômero III mais longo que o escapo e trocanteres dos machos nãoprolongados em espinho separam Piezosecus de Colynthaea Thomson, 1878.

\section{Piezosecus tymaiuba sp. nov.} (Figs. 1-4)

Etimologia. Tupi, tymã = perna; iuba $=$ amarelo; alusivo à coloração dos fêmures.

Cabeça, protórax, élitros, face ventral e tarsos castanhoavermelhados. Antenas e tíbias desde castanho-avermelhadas até pretas. Fêmures amarelados com os ápices pretos. Vértice com escultura irregular, microesculturado nas depressões. Antenas (Fig. 1) com pêlos longos, principalmente no lado interno; escapo, pedicelo e antenômero III pontuados; pontuação gradualmente mais tênue em direção aos antenômeros apicais. Pronoto com pontos alveolados, microesculturados internamente; pêlos esparsos. Prosterno pontuado principalmente na metade posterior. Metasterno pontuado na base e nos lados. Pontuação elitral densa na metade anterior e gradualmente pouco mais esparsa na metade apical. Metepisternos com pubescência serícea. Fêmures lisos. Pernas e face ventral com pêlos esparsos.

Dimensões, em mm, macho/fêmea. Comprimento total, 13,422,1/13,3; comprimento do protórax, 2,5-3,7/2,3; maior largura do protórax, 2,6-4,3/2,3; comprimento do élitro, 9,3-15,9/9,6; largura umeral, 3,1-5,6/3,1.

Material-tipo. Holótipo macho, BRASIL, São Paulo: Araras, 13.X.1981, S. M. Nunes col. (MZSP). Parátipos. Bahia: Condeúba, macho e fêmea, I.1976, S. Souza col. (DZUP); Espírito Santo: Barra do São Francisco (Córrego do Itá), 2 machos, X.1954, W. Zikán col. (MZSP).

\section{Ibidionini (III ${ }^{a}$ Divisão) \\ Gnomibidion variabile sp. nov.}

Cabeça inteiramente avermelhada ou avermelhada com a fronte, os tubérculos anteníferos, as genas e estreita orla atrás dos olhos, pretos. Antenas pretas ou avermelhadas. Protórax e escutelo avermelhados. Élitros avermelhados com o quinto apical preto. Fêmures avermelhados com a ponta enegrecida em pequena extensão ou inteiramente pretos. Tíbias e tarsos 

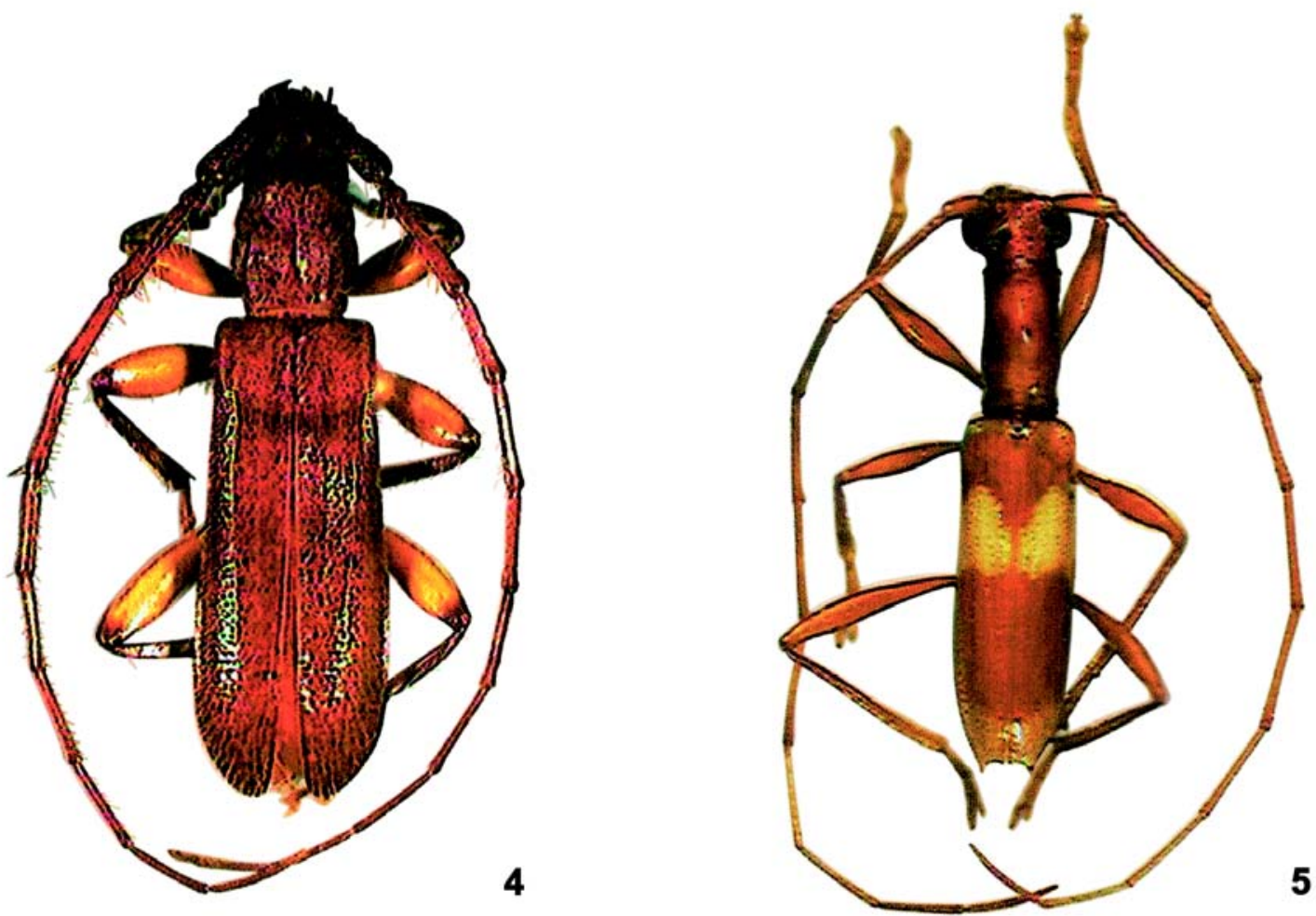

Figs. 4-5. 4, Piezosecus tymaiuba sp. nov., parátipo macho, comprimento, 13,4 mm; 5, Palpibidion minimum sp. nov., holótipo macho, comprimento, $7,9 \mathrm{~mm}$.

avermelhados ou pretos. Face ventral do corpo avermelhada.

Tubérculos anteníferos agudos. Lobos oculares superiores com quatro a seis fileiras de omatídios. Antenas dos machos alcançam o ápice elitral, aproximadamente, na extremidade do antenômero VI e, nas fêmeas, no ápice do VII. Escapo subpiriforme com sulco no lado superior da base. Antenômero III finamente carenado.

Protórax evidentesmente mais longo do que largo, constrito no quarto anterior e no sexto basal. Pronoto com cinco tubérculos: dois anteriores arredondados no topo; um central, mais próximo dos anteriores e dois basais. Superfície pronotal sem pontos e sem pubescência. Prosterno finamente rugoso na metade anterior; duas faixas largas de pubescência serícea esparsa na metade basal.

Élitros com alguns pontos ásperos na base que se prolongam, no meio, em três fileiras longitudinais, dorsais. Extremidades elitrais cortadas em curva estreita e com espinho externo. Metatíbias carenadas.

Dimensões, em mm, macho/fềmea. Comprimento total, 14,416,9/15,8-16,0; comprimento do protórax, 3,4-4,1/3,5-3,6; maior largura do protórax, 2,1-2,6/2,1-2,3; comprimento do élitro, 9,511,2/11,1-11,2; largura umeral, 2,7-3,5/3,1-3,2.

Material-tipo. Holótipo macho, BRASIL, Mato Grosso: Vera (1246’S, 5536'W), X.1973, Alvarenga \& Roppa col. (MNRJ). Parátipos. Fêmea, mesmos dados do holótipo (MNRJ); Amazonas: Manaus (Instituto Nacional de Pesquisas da Amazônia), macho, 27.X.1976, I. S. Gorayeb col. (MZSP); fêmea, ditto, 25.XI.1976, I. S. Gorayeb col. (MPEG).
Discussão. No gênero Gnomibidion foram reconhecidos dois grupos de espécies (MarTins 1968: 580). Gnomibidion variabile pertence ao grupo II que se caracteriza pelo pronoto com elevação central pouco pronunciada e que reúne $G$. translucidum (Martins, 1960) e G. occultum Martins, 1968. G. variabile difere de ambas pelos élitros sem manchas claras.

\section{Ibidionini (IV ${ }^{\mathrm{a}}$ Divisão) \\ Palpibidion gen. nov.}

Espécie-tipo: Palpibidion minimum sp. nov.

Tubérculos anteníferos levemente projetados, subacuminados no topo. Olhos não-divididos; lobos oculares superiores estreitos com três fileiras de omatídios, tão distantes entre si quanto o triplo da largura de um lobo. Antenas com 11 artículos; nos machos, tão longas quanto o dobro do comprimento do corpo. Escapo subcilíndrico, ligeiramente engrossado para a extremidade; tão longo quanto a metade do comprimento do antenômero III. Antenômero III nãoengrossado, com uma fina carena dorsal e setas muito esparsas no lado interno; aproximadamente um terço mais longo que o IV; antenômero IV pouco mais curto do que o V; antenômeros VI a XI com comprimentos gradualmente decrescentes. Protórax cilíndrico; comprimento igual ao dobro da largura; pouco mais estreito ao nível do terço anterior e mais alargado ao nível do terço posterior. Pronoto desnudo com tubérculo pouco à frente 
do meio. Prosterno com pubescência serícea esparsa em forma de "V" na metade basal. Élitros sem áreas de pubescência serícea; extremidades cortadas em curva com espinho curto no lado externo e projetadas no ângulo sutural. Profêmures pedunculados, levemente engrossados no meio e afilados para a extremidade. Metafêmures longos; os ápices quase atingem a ponta dos élitros; abas apicais ligeiramente projetadas. Metatíbias finamente carenadas. Metatarsômero I igual a II+III.

\section{Palpibidion minimum sp. nov.}

(Fig. 5)

Colorido geral vermelho-alaranjado. Último artículo dos palpos labiais e maxilares fortemente securiforme. Élitros mais amarelados no quinto basal; cada um com uma mancha branca, localizada à frente do meio, estreitada na margem anterior para o lado da sutura e subtransversal na margem posterior; extremidades ocupadas por mancha esbranquiçada. Protórax praticamente liso. Pronoto (40x) com pontos muito pequenos e muito esparsos. Élitros com duas fileiras longitudinais de pontos pilíferos muito distantes, uma do lado da sutura e outra na declividade lateral.

Dimensões, em mm, macho. Comprimento total, 7,1-7,9; comprimento do protórax, 1,8-2,0; maior largura do protórax, 1,0-1,1; comprimento do élitro, 4,4-5,0; largura umeral, 1,4-1,5.

Material-tipo. Holótipo macho, BRASIL, Rondônia: Ouro Preto, VIII.1980, B. Silva col. (MNRJ). Parátipo macho, BRASIL, Mato Grosso: Sinop (Rodovia BR-163, km 500-600, 350 m), X.1975, Roppa \& Alvarenga col. (MZSP).

Discussão. O último artículo dos palpos, pelo menos nos machos, é acentuadamente alargado para o ápice. Palpibidion, apesar de pertencer à IV ${ }^{\text {a }}$ Divisão (MARTINS 1969) pelo protórax muito longo, lembra as espécies do gênero Gnomibidion que pertence à III ${ }^{a}$ Divisão, mas o escapo é subcilíndrico, desprovido de sulco no lado superior da base, os tubérculos anteníferos não são acuminados, os fêmures são mais alongados e os élitros apresentam somente duas fileiras de pontos muito distantes.

Dos gêneros da IV ${ }^{\mathrm{a}}$ Divisão, difere de Ibidion pelas menores dimensões, pelo escapo sem rugas e pela ausência de pêlos amarelados, duros e muito alongados em todo o corpo.

Agradecimento. A Jorge Luiz Dutra Soledar (Museu de Ciências Naturais, Porto Alegre) pela execução das fotografias.

\section{REFERÊNCIAS}

Galileo, M. H. M. \& U. R. Martins. 2000. Novos táxons e nova combinação em Cerambycinae (Coleoptera) sul-americanos. Papéis Avulsos de Zoologia 41(10): 155-172.

Martins, U. R. 1967-1971. Monografia da tribo Ibidionini (Coleoptera, Cerambycinae). Partes I-VI. Arquivos de Zoologia 16(6): 1-1508, 30 est.

Martins, U. R. 1971. Notas sobre Cerambycinae VI (Coleoptera, Cerambycidae). Subsídios ao conhecimento dos Ibidionini. Arquivos de Zoologia 21(3): 121-178.

Martins, U. R. 1976. Sistemática e evolução da tribo Piezocerini (Coleoptera, Cerambycidae). Arquivos de Zoologia 27(3/4): 165 370 .

Martins, U. R. \& M. H. M. Galileo. 1999. Novas espécies de Ibidionini (Coleoptera, Cerambycidae) da América do Sul. Revista Brasileira de Entomologia 43: 301-307.

Martins, U. R. \& D. S. NAPP. 1986a. Ibidionini (Coleoptera, Cerambycidae). III ${ }^{a}$ Divisão: descrições, notas e chave para espécies de Minibidion. Revista Brasileira de Entomologia 30: 5-12

Martins, U. R. \& D. S. NApP. 1986b. Ibidionini (Coleoptera, Cerambycidae). $\mathrm{V}^{\mathrm{a}}$ Divisão: descrições e notas. Revista Brasileira de Entomologia 30: 227-241.

NAPp, D. S. \& U. R. Martins. 1985a. Ibidionini (Coleoptera, Cerambycidae).

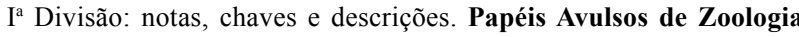
36: $111-130$.

NAPP, D. S. \& U. R. Martins. 1985b. Ibidionini (Coleoptera, Cerambycidae). IV ${ }^{a}$ Divisão: descrições, sinonímias e chave para espécies do gênero Cycnidolon Thomson, 1864.

Papéis Avulsos de Zoologia 36: 131-146. 